\title{
Social Media as a New Form of Public Sphere
}

\author{
Erlis Çela, PhD. Cand. \\ "Hëna e Plotë" Bedër University \\ ecela@beder.edu.al
}

Abstract

\begin{abstract}
The public sphere is a concept widely studied from many different disciplines such as political sciences, sociology, dhe communication sciences. It is crucial for the well-functioning of democracy, to have a well-structured process which creates the public opinion as a synthesis of individual thoughts acting for the common interest. The concept public sphere in itself and its formation process has gone through a lot of changes since the time where the german scholar Jurgen Habermas brought for the first time its definition. The appearance of the new medias and the development in the communication technology have brought huge transformations even in the conceptual term of public sphere and public discourse. Web communication, especially the communication handled in the dixhital environment is a completely new reality which needs to be explored. Social Media like Facebook, Twitter, Instagram, Youtube etc, are a new communication field being used from the public factors to communicate with the audiences. The technical opportunities that these platforms offer make it possible for the transmitter and the receiver of the message to communicate in a higher level. In contrast, virtuality serves as an inducement mean for the users in the social network to be near the participators in the process of communication.
\end{abstract}

Keywords: Public sphere, political communication, social media, cyberspace, e-participation

\section{Introduction}

\section{Public Sphere according to Habermas}

Media have an important role in the social changes by powering the public sphere. Seen from the historical context different scholars have agreed that media plays a really important role in shaping our own ideas and establishing our position in society. The german sociologist and philosopher Jurgen Habermas in his book "The structural transformation of the Public Sphere", argues that the press have contributed in the democratization of Europe by creating an environment suitable for discussion and agreements between the citizien involved politicaly. The political freedom should be accompanied with an educated civilized society and socially aware to discuss events that are related with the public's interest. Similar to the masmedia case, internet and especially the social media, allows the individuals to discuss and express their thoughts in public regarding events which have a wide public interest (Shirky, 2011)

Habermas in his book opposes, according him the feudal domination of involvement in the public communication. Habermas put against this concept the public communication with two-direction, that of equality and the one oriented toward the consensus which would be able to create a real (possibility) and relevant public space for politics. For the civilian public sphere presented from Habermas as public discussion arena, informed and resonating, the independent press based on the free market has an important significance. This press should be accessible for a large amount of people and inside it should be involved different arguments and point of views as a part of rational discussions. Inside this public space are discussed even the governmental politics which are part of critical thinking. According to Habermasit after the second half of the 19 century in the capitalist societies, the situation was completely different, where the realization of the representative democracy was quite impossible due to the dominion of the public sphere from the strong and widespreading state and due to the press which represented the economic interests. Medias from the position of being a part of public sphere and racional discution are becoming a part of refeudalisation process of public sphere, where state, industrial corporates and media control the public sphere. According to Haberman in these societies medias are turned into a deceiver tool by turning the public into a passive consuming audience. The public space in theories involving participations is characterized from the equal acceptance of the factors that dicuss, from the reciprocal connection of communication and through a structure which offers possibilities to be involved in a discourse and does not exclude in a structural manner certain thoughts or certain complex themes. (Habermas, 1991, p. 31). 
Despite what it is stated above, the theory of Habermas for the rational public sphere and opinion was criticized a lot form the critics who bring new arguments. The main criticism is related with the fact that the concept of the public sphere is an elite concept and most propably utopian that have never existed. Meanwhile another criticism comes from the feminist movement which states that Habermas creates a public sphere that does not include all the components of the society such as: women or representatives form the lowest class of society. (Papacharissi, 2002, p. 11).

\section{Cyberspace and the internet as the new forms of the public spheres.}

The development of new technologies such as communication and the arousing of the new media based on Web 1.0 and Web 2.0, brought another new dimension in the discussion of the public sphere. The public sphere or the public space where takes place debates that have a wide interests in public and where is developed a critical reflections toward the governmental policies is strictly related with the media and technology. Starting from the time when the newspaper in the United Kingdom expand their functionality by adding opinions, criticism and comments beside the news, facilitating in this way the debate between the bourgeoisies and the educated class of society and up to our days where the social media as the newest product in the revolution of the communication technology, "Public sphere" and "public opinion" are both terms that are strongly related with the functions of media and the democratic representative theory. (Mecnair, 2009, p. 32) (Boyd, 2011, p. 53). After the innovation of internet, the scholars brought to attention a differentiation of the public sphere and public opinion from their classical meaning and a new notion "networked public sphere", where the public opinion is shaped through exchanges in the online platforms. Cybersecurity space known different as "cyberspace" currently is a new public space.

Internet as a new public sphere can facilitate the discussion that promotes the exchanging of new ideas and opinions. (Papacharissi, 2002, p. 11). The exchanging of ideas and the interaction between the individuals has reached the higher level thanks to the using of social media platforms like facebook, twitter dhe youtube. These users can communicate freely with each-other and consequently can come together for a certain theme. Communicating online means to publish online which on the other hand refer to be connected online with other people. The published content in the social media is reachable from anyone throughout the world eliminating in this way the physical and infrastructure obstacles which means that the freedom of the speech is now the freedom of the press and as a consequence the freedom to gather together. (Fuchs, 2014, p. 185). It was never as easy as it it is now for the people to come together and be organized to express their criticism or to contradict a certain matter that concerns a certain community.

The Albanian environment (context) offers a wide variety of examples that shows that the users of the social media thanks to the opportunities to build virtual communities and use virtual communications, have the possibility to be organized and discuss, debates and oppose a certain political action or a certain wrong decision. The well-spreaded news about the dismantling of the chemical weapons of Syria will tool place in Albania caused a strong reaction in the public opinion. Taking into consideration that the televisions or the newspaper were not giving the necessary importance to this matter, purposely or not, a community in Facebook organized a campaign which made together a huge number of people. Within a short time the Facebook page against the Dismantling of the Chemical Weapons in Albania reached a big number of followers. This profile served to organize the opponency grouping in the protests held that time.

Such protests case against the chemical weapons is a pure example for showing how the social media make it possible to develop e public discussion by serving as an alternative public sphere where is shaped the public opinion. As e result this opinion has reached the higher level of acceptance from a wide class of society. The government was forced to reject this project due to the strong opponence from the public opinion in order to refuse the request made from the American government to dismantle these weapons in the albanian territory. The official profile of the Albanian primeminister in the facebook network was so full of comments and criticism which were related with this matter that forced the primeminister to pay a bigger attention to clarify the users on the facebook than the ones who spoke in the television.

\section{The social capital and the "Community" effect in creating the public sphere.}

Marius Rohde Johannessen in his study "Social media as public sphere" argues that the communication thorugh the social media can contribute in developing the discussion and the public debate. According to him, the creation of the public 
sphere becomes easier from the "social capital" and the building of community (community building) in the social media. These communities facilitate the communication between the individuals who have come together due to the common interests, despite the fact that they can share different opinions for other matters which are not part of this community creation in the social media. (Johannessen, 2013, p. 79)

The social capital is related with the connection between the individuals and the social networks and the mutual credibility and norms that comes as a consequence. In contrast, the social capital evokes the financial and human capital dimension but it is mainly focused in the relation between the individuals. The previous studies have discovered a direct connection between the social capital and the usage of the social networks (Ellison, Lampe, Steinfield, \& Vitak, 2011, p. 128) (Stutzman, Vitak, Ellison, Gray, \& Lampe, 2012, p. 330). The social networks give the opportunity to the individuals to maintain some connections that in reality might be weak and in the "offline" reality would be quite impossible to hold and manage. For example, Facebook gives the opportunity to the individuals to communicate and interact virtually with "the friends of the friends", by expanding in this way their communication network

It is important to mention that the social capital is very complex to be measured. In most of the cases the measurement or assessment of the social capital is related with the level of credibility the involved institutions or individuals have in the public sphere. At the same time, exists a proportional report between the social capital and the participation in the context of the public sphere. The high level of the social capital serves to increase the participation or the e-participation as in the case of the social media and the high level of participation produces more social capital. (Johannessen, 2013, p. 99).

The theory of e-participation is the one that bounds the networked public sphere with the social media. In one report from the United Nations Organization in 2010 for "e-government" emphasize the importance that the e-participation has in all its aspects: e-information, e-consulting and e-decision. This report assess the way how the governments interact with their individuals using the blogs, SMS, and social media like Twitter and Facebook. According to the same report, web 2,0 and the social media have created a new environment where the public institutions can create a better interactive connection with the public. (Pereira, Rocha, \& Popli, 2012, p. 492)

The necessity to reinforce the social capital and the necessity to communicate within the community are two main reasons that stimulate the users of the social media to build what is called the dimension of the public sphere in the social media. The users of the social media are likely encouraged to express freely their thoughts and opinions in a virtual community 
stimulating in this way the public debate which produces the public opinion which it in itself compounds the final product of the communicating process within the public sphere.

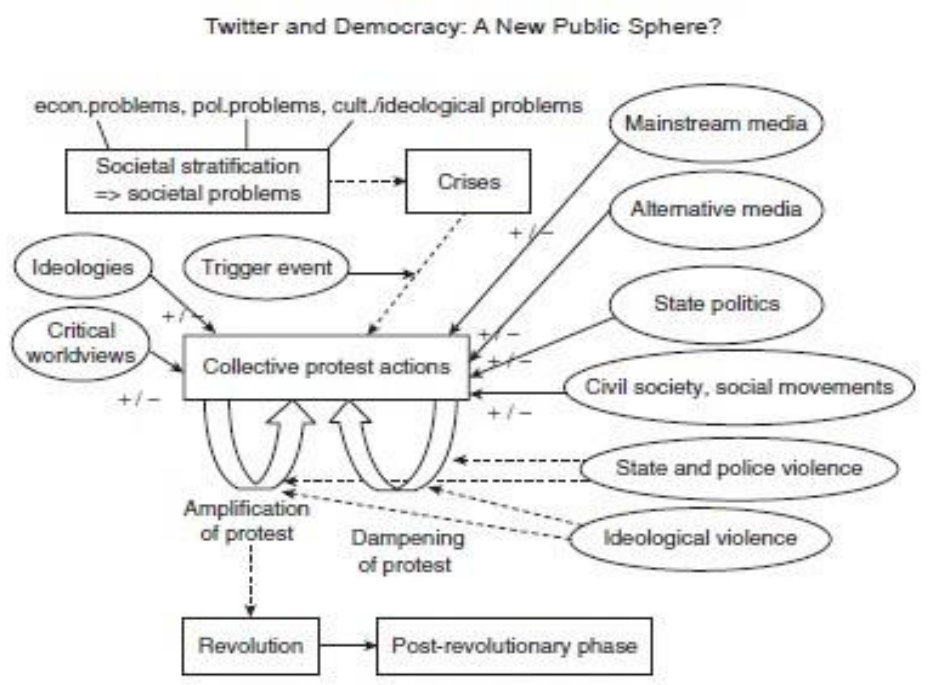

\section{Figure 1. Christian Fuchs Model}

\section{Social Media's shades as a new public sphere in the Albanian reality.}

In most of the cases, the studies related with the creation of the public sphere refers to the post-communist era which begins with the falling of the dictatorial regime and the beginning of the political pluralism in 1991. If we follow the Habermas concept on the public sphere as a space where is formed the opinion public, then it is very difficult to speak for a real public sphere in the communist era. The freedom of speech,- the freedom of the press are basic concepts that in case they are missing we can not discuss for having a public space or public sphere. After the falling of communism, the Albanians started to express freely their thoughts and opinions related to the social and political development and the important factors included in these developments.

The arousing of the free press, create the opportunity to speak up the critical thinking. The scholar Artan Fuga describes this situation as a noisy beginning after a long public silence. He emphasizes the fact that Albanians after the fall of communism discovered that "the other person" was not dangerous to speak to. This discovery made an important change in the mentality of Albanian society. According to Fuga, this is the moment where the "oral taboo" of the past are broken and is surpassed the border of the "allowed discussion" (Fuga, 2008, p. 20).

On the other hand, the scholar and sociologist Fatos Tarifa sees that after the 1990 begins to create a liberal and modernise public sphere. The free exchange of the ideas and opinions accompanied with a wider space to publish these new ideas in the uncensored press has created a better normal process to shape the public opinion. Tarifa notices that creating a liberal public sphere, informal and discoursive aroused in the higher level the interest of the Albanians for the public cases. According to him, Albania and other neighbor countries which suffered the post-communism era share similiarities in creating the public sphere with the same public sphere created in Europe during the 18 and 19 century. The new public sphere created a space for forming the autonomus organization acting together as one group which made the essence of the civil society (Tarifa, 2014, p. 48)

Starting from the fact that the liberal public sphere in Albanian is smiliar to the one created in Europe in the 18 and 19 century, shows that the Albanian society has made no progress in the past and it is necessary to implement a fast rhythm 
to recuperate the lost time. It took many centuries to the Europe to transform the civilized society into a bourgeois system (Kabo, 2006, p. 236). In Albania, there was no such patience to wait for such a long time, so the development in the communication and the public sphere was in its higher rhythms. Even why this anticipation brought in itself a lower quality during the transformation period, the development of the Medias and the communication spaces were hand in hand. At the beginning, the Albanians were eager to be informed from new and "free" sources. They have just gone through a big isolation and the necessity to be informed without censure and to express themselves in the same way was the major characteristic in those years after the communism era. This big appetite of the Albanian society served as the prefect environment where a large number of media will arouse. Starting from the first opposition newspaper"Rilindja Demokratike" on January 4, 1991, with the creation of the first private televisions like "Tv Sijak" and later with "Tv Klan" in 1997. With the passing of the years, to the list of the television were added numerous nonpublic operator which created a very liberal picture in the world of Albanian media. In 1998 there were 31 television stations all over Albania including here local station placed in different cities. (Fuga, 2008, p. 50). It has not passed almost one decade when to the Albanian public was introduced the first web informative portal named "balkanweb"

The online media registered an important development regarding the public discourse. From now on we dealt with new factors in the political communication and the public space was enlarged. In the second decade, after the political pluralism, we encounter a huge development in the field of media and communication technology. The number of the online medias was very high and without noticing their importance and impact, we saw the arousing of the social media with facebook in 2004 and twitter in 2006. The Albanian again hurried to try the benefits that these new Medias brought. In a very short time the number of the users who used the social network counted "hundred \& thousand". Taking into consideration such situation we have a reposition of the public discussion. Nowdays the politicians and the other public actors have understood the benefits offered from "cyberspace" which added to the public discourse the "virtual" element. From a fast observation made in the social media results that the official profiles and pages of the politicians are the ones which are the most followed. They use these new spaces to communicate with the public, voters, followers and groups of interest.

Table 1 The statistic data of the four politician profiles most followed in Facebook.

\begin{tabular}{|l|l|}
\hline Politician & Nb. of followers \\
\hline Sali Berisha & 991056 \\
\hline Edi Rama & 879247 \\
\hline Lulzim Basha & 546990 \\
\hline Erion Veliaj & 245480 \\
\hline
\end{tabular}

In the same way, the political campaigns are transferred from gathering grouping in the squares toward question-answer sessions in Facebook, Twitter and Youtube. Lulëzim Basha campaign in 2011 for the local election in Tirana was based in the social media. He built a successful campaign in Facebook achieved to engage a considerable audience from the young users who used such networking.

The main important items of the program were released in Facebook and a particular team analysed the numerous comments and questions that were made in the democratic candidate profile. In this way, they build an effective interaction communication with the active individuals in this network

This new style of communication and the effective usage of the social media can't be considered as Albanian invention. In politics similar to the many other fields, the model to be followed is taken from United States of America. The campaign of the president Barack Obama in 2008, srved as a model and showed the importance of using the social media for building a public communication with an audience who had changed its address from that of the squares to the computers and "smarphone". The studies shows that the social network has rised the participation in the political debate and consequently the political process, because through them is lowered the cost of the political information and the infrastructure to share this information with the others is facilited in its highest level (information share). (Johnson, Zhang, Bichard, \& Seltzer, 2011, p. 191) 


\section{Conclusion}

If we compare the countinous increasing number of the users in the social networks around the world with the countinous declining of the newspaper circulation or the traditional media audience in general, it is clear that now we are living in a new era of information and communication. The social media and in general the virtual sphere is drawing more and more people, which on the other hand has a direct impact on their behavior in the non virtual reality. The communication of the political messages is now communicated mainly through virtual environment. This new trend seems for the moment to be satisfactory for both parties, the one who is producing this information and on the other side the consumer of this information (its user). Thanks to the social media the borders between the provider of the information and the consumer of this information are completely invisible. Meanwhile, on the other hand, this new phenomenon has made the communication more democratical by empowering the simple people who were very passive in the past. The Albanian reality shows that the politic and public discourse is taking place in a virtual environment. But it is important to emphasize that the later studies should be concentrated in studing the possible negative effects of this transformation.

\section{Bibliography}

[1] Boyd, D. (2011). Social Network Sites as Networked Publics; Affordances, Dynamics, and Implications. In Z. Papacharissi, A Networked Self, Identity, Community, and Culture on Social Network Sites (pp. 49-63). New York: Routledge.

[2] Ellison, N. B., Lampe, C., Steinfield, C., \& Vitak, J. (2011). How Social Network Sites Affect Social Capital Processes. In Z. Papacharissi, A Networked Self. Identity, Community, and Culture on Social Network Sites (pp. 124-145). New York: Taylor \& Francis.

[3] Fuchs, C. (2014). Social Media, A critical introduction. London: Sage Publication.

[4] Fuga, A. (2008). Media, politics, society (1990-2000) Running away from Rozafa Complex . Tirana: Dudaj Edition.

[5] Habermas, J. (1991). The Structural Transformation of Public Sphere. Cambridge, Massachusetts: The MIT Press.

[6] Johannessen, M. R. (2013). Social media as public sphere. Kristiansand: Printing Office, University of Agder Kristiansand.

[7] Johnson, T. J., Zhang, W., Bichard, S. L., \& Seltzer, T. (2011). United We Stand? Online Social Network Sites and Civic Engagement. In Z. Papacharissi, Networked Self. Identity, Community, and Culture on Social Network Sites (pp. 185-207). New York: Taylor \& Francis.

[8] Kabo, P. (2006). Authoritarianism during transition.Albanian anthropology through globalization. Tirana: Plejad Edition.

[9] Mecnair, B. (2009). Introduction into politic communication . Tirana: Uet-Press.

[10] Papacharissi, Z. (2002). The virtual sphere: the internet as a public sphere. new media \& society, Vol.4 (1), 9 27.

[11] Pereira, G. C., Rocha, M. C., \& Popli, A. (2012). e-Participation: Social Media and the Public Space . 12th International Conference on Computational Science and Its Applications (ICCSA 2012) (pp. 491-501). Salvador de Bahia, Brazil: Institute of Electrical and Electronics Engineers.

[12] Shirky, C. (2011, January). The political power os social media. Foreign Affairs, pp. 1-9.

[13] Stutzman, F., Vitak, J., Ellison, N. B., Gray, R., \& Lampe, C. (2012). Privacy in Interaction: Exploring Disclosure and Social Capital in Facebook. Sixth International AAAI Conference on Weblogs and Social Media (pp. 330337). Dublin: AAAI Press.

[14] Tarifa, F. (2014). Sociological imagination and our social world. Tirana: Onufri Edition. 